\title{
ОЦЕНКА АКТИВНОГО ДОЛГОЛЕТИЯ В СИБИРСКОМ ФЕДЕРАЛЬНОМ ОКРУГЕ НА ОСНОВЕ МЕТОДИКИ ИНДЕКСА АКТИВНОГО ДОЛГОЛЕТИЯ
}

\author{
Фролова Елена Александровна 1 , \\ frolova_ea@mail.tsu.ru \\ Кашапова Эльмира Рамисовна², \\ elmira6280@yandex.ru \\ Клемашева Елена Игоревна², \\ klemaha@mail.ru \\ Маланина Вероника Анатольевна², \\ milanskaya@mail.ru
}
${ }^{1}$ Национальный исследовательский Томский государственный университет, Россия, 634050, пр. Ленина, 36.
${ }^{2}$ Национальный исследовательский Томский политехнический университет, Россия, 634050, пр. Ленина, 30.

\begin{abstract}
Фролова Елена Александровна, доктор экономических наук, профессор кафедры экономики Института экономики и менеджмента Национального исследовательского Томского государственного университета.
\end{abstract}

Кашапова Эльмира Рамисовна, лаборант Международной научно-образовательной лаборатории технологий улучшения благополучия пожилых людей Национального исследовательского Томского политехнического университета.

Клемашева Елена Игоревна, лаборант Международной научно-образовательной лаборатории технологий улучшения благополучия пожилых людей Национального исследовательского Томского политехнического университета.

Маланина Вероника Анатольевна, кандидат экономических наук, доцент отделения социальногуманитарных наук Школы базовой инженерной подготовки Национального исследовательского Томского политехнического университета.

В мировой науке изучение процесса активного долголетия началось относительно недавно - в Европе попытки комплексного количественного анализа процесса активного долголетия впервые были предприняты в 2010 г. Целью данной работы является количественная оценка процесса активного долголетия в Сибирском федеральном округе. Авторы выявили методологические проблемы применения международной методики оценки активного долголетия для России и отдельных регионов. Методы: метод индексной оценки социально-экономических процессов, формирующих основу активного долголетия, в частности Индекс активного долголетия (Active Ageing Index). Для иллюстрации отдельных выводов дополнительно использованы данные опросов людей старшего поколения Томской области и результаты экспертных семинаров, проведенных Международной лабораторией улучшения технологий благополучия пожилых людей ТПУ с участием пенсионеров и социальных работников. Результаты. Проведенные оценки индикаторов и доменов Индекса активного долголетия позволили выявить наличие нереализованного потенциала активного долголетия в Сибирском федеральном округе. Значительные негативные отклонения от среднероссийских значений наблюдаются в отношении занятости пожилых людей, отсутствия риска бедности, физической безопасности и включенности в социальные связи. Вместе с тем Сибирь показывает 
более высокие результаты по физической активности, относительному среднему доходу и отсутствию сильной материальной депривации. Показатели финансовой обеспеченности пенсионеров Сибирского федерального округа свидетельствуют об их относительном благополучии на фоне молодого поколения, однако низкие доходы по региону в целом создают предпосылки для высокого риска бедности.

Ключевые слова: Активное долголетие, Индекс активного долголетия, пожилые люди, Сибирский федеральный округ, Томская область, социальная активность.

\section{Введение}

С возрастом физические и интеллектуальные возможности человека сокращаются. Проблема старения населения является реальностью для стран Европы, где значительная часть населения - это люди пенсионного возраста. Развивающиеся страны Индия и Китай - также осознают перспективы воздействия роста количества пожилых людей на экономическую и социальную обстановку в своих странах в ближайшие десятилетия. Основная идея исследований в данной области - сформировать отношение к пожилым людям не только как к реципиентам пенсий, социальной и медицинской помощи, но как к индивидам, способным вносить существенный вклад в повышение качества своей жизни и жизни окружающих $[1,2,3]$. Следовательно, необходимо рассматривать два основных аспекта активного долголетия - теоретический и практический. На уровне теории необходимо выявить все значимые факторы, определяющие содержание и динамику процесса активного долголетия. Практическая проверка значимости данных факторов требует анализа обратной связи, получаемой от старшего поколения через опросы общественного мнения.

Активное долголетие затрагивает не только возрастную группу лиц 60 лет и старше, оно трактуется как процесс, участие в котором начинается с момента вступления индивида в трудоспособный возраст. Комплексного анализа требует социальноэкономическая политика в отношении нынешних и будущих когорт пожилых граждан. Всемирная организация здравоохранения полагает, что целями глобальной стратегии обеспечения активного долголетия должна стать приверженность каждой страны обеспечению активного долголетия на основе конкретных проблем, с которыми сталкиваются пожилые граждане. В некоторых странах к этим проблемам относится эйджизм, в других - высокий уровень заболеваемости, в третьих - отсутствие целостной пенсионной политики. Тем не менее общие ориентиры определены ВО3 как создание agefriendly среды, адаптация национальных систем здравоохранения к специфическим нуждам пожилых, развитие систем долговременного ухода [4]. Все вышеуказанные цели должны реализовываться с учетом мнений и предпочтений пожилых людей (относительно проживания дома или в специализированных учреждениях) и при их непосредственном участии, когда таковое возможно.

Соответственно, изучение особенностей личного выбора индивида и государственной социально-экономической политики, оказывающей воздействие на этот выбор в трудоспособном возрасте в контексте образования, выбора профессии, количества детей в семье, может обеспечить большую независимость пожилых людей от посторонней помощи и их активность в пожилом возрасте [5]. В условиях фактического повышения пенсионного возраста в России важно проследить в динамике изменение роли различных форм занятости в процессе старения в возрасте 55+ для женщин и 60+ для мужчин в новых институциональных условиях $[6,7]$.

В силу объективного сокращения физических возможностей (главным образом в силу состояния здоровья) важным условием активного долголетия выступает среда: 
доступность медицинской помощи, физическая доступность учреждений и транспорта для людей с ограниченными возможностями, безопасность по месту постоянного проживания. Бенефициарами проектов по развитию доступности и безопасности среды являются представители всех возрастных групп, что экономически оправдано и вписывается в расширенную концепцию «активного долголетия». Также наблюдается существенное региональное неравенство условий жизни населения в целом. Потенциал инновационно активных регионов, промышленных центров, сырьевых монопрофильных регионов определяет существенные различия в уровне бюджетной обеспеченности регионов, различия региональных рынков труда и неравенство в доступе к объектам социальной инфраструктуры. Все это оказывает влияние на возможности реализации принципов активного долголетия в российских регионах, формируя ощутимый разрыв между городами и сельскими районами.

Соответственно, существует огромный потенциал улучшения качества жизни пожилых людей через целенаправленное воздействие на компоненты процесса активного долголетия. В России аналогичных исследований практически нет, но, учитывая существующие демографические тенденции, проблема проектирования и управления процессом активного долголетия является актуальной. Однако, несмотря на накопленный опыт, в региональном контексте РФ параметры активного долголетия до сих пор не являются объектами регулярного мониторинга, что потенциально снижает эффективность инструментов региональной и местной социальной политики, направленной на обеспечение высокого качества жизни и благополучия населения.

\section{Демографические аспекты старения населения в Сибирском федеральном округе и Томской области}

Сибирский Федеральный округ объединяет субъекты с разными демографическими трендами: по прогнозу в 2050 г. максимальный прирост населения ожидается в Республике Тыва (+56,9 \%), в Алтайском крае - значительная убыль населения $(-23,9 \%)[8]$. За счет повышения официальной границы пенсионного возраста всем субъектам СФО к 2050 году удастся существенно замедлить темпы роста демографической нагрузки пожилыми (отношение количества населения в нетрудоспособных возрастах к трудоспособному населению старше 20 лет, умноженное на 100). Однако, несмотря на снижение демографической нагрузки в условиях нового пенсионного возраста по сравнению со старым, ее уровень все равно превысит значение 50 во всех субъектах СФО за исключением трех (Красноярский край, Республика Алтай и Тыва) (см. рисунок).

В целом тренд для Томской области соответствует другим субъектам РФ: за период 2012-2018 гг. доля старшего поколения в общей численности населения последовательно прирастала на 0,2-0,5 п.П. каждый год. Старение населения является текущей актуальной тенденцией развития социальной ситуации в Томской области. Согласно данным Росстата, на 2018 г. в Томской области проживают 246 тыс. пенсионеров, что составляет 22,9\% всего населения [9].

\section{Методология исследования}

В качестве опорной методологии использован комплексный Индекс активного долголетия, разработанный профессором А. Заиди и соавторами $[10,11]$. Индекс представляет собой 22 индикатора, сгруппированных в четыре домена (сферы). Первый домен «Занятость» включает уровень трудовой занятости пожилых людей по различным возрастным группам (55-59 лет; 60-64 года; 65-69 лет и 70-74 года). Второй домен «Участие в жизни общества» включает оценку вовлеченности в деятельность добро- 
вольческих организаций, заботу о детях, внуках и других пожилых людях и различные формы участия в политической деятельности (от участия в митингах до встреч с представителями власти). Третий домен «Независимая, здоровая и безопасная жизнь» дает количественные оценки физической активности, доступности медицинских и стоматологических услуг, независимому проживанию пожилых граждан старше 75 лет, относительному медианному располагаемому доходу, отсутствию риска бедности, отсутствию серьезной материальной депривации, физической безопасности и обучению в течение жизни. В четвертый домен «Возможности для активного и здорового долголетия» вошли индикаторы относительной ожидаемой продолжительности жизни в возрасте 55 лет, доля лет здоровой жизни в возрасте 55 лет, психологическое благополучие, использование информационно-коммуникационных технологий, социальные взаимодействия и наивысший полученный уровень образования. Каждый индикатор в домене имеет свой вес, итоговые значения всех индикаторов сводятся в интегрированное значение Индекса активного долголетия для региона или страны.

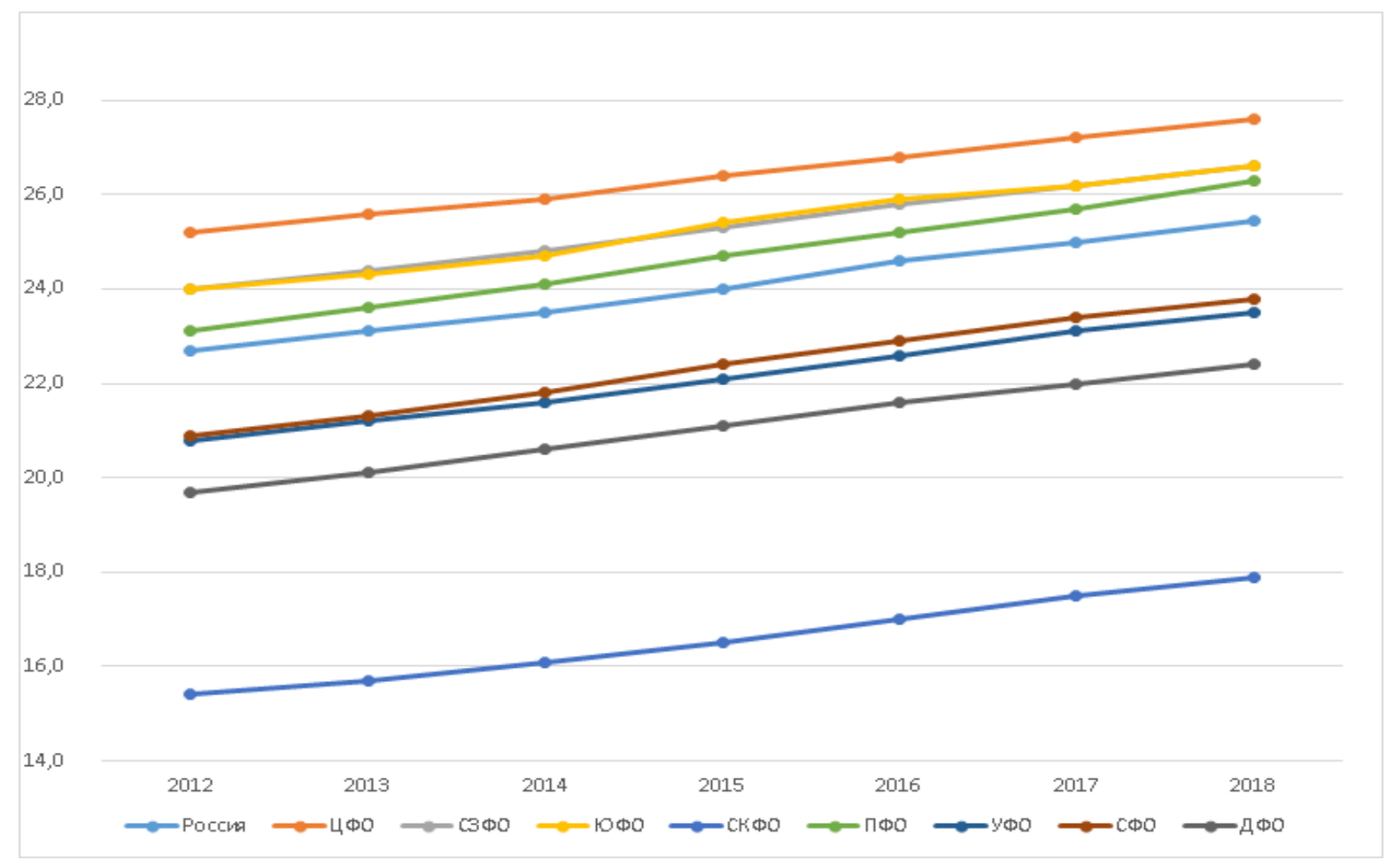

Рисунок. Доля населения в возрасте старше трудоспособного в федеральных округах РФ [8]

Figure. Share of individuals above legal pension age in Russian Federal districts [8]

Изначально Индекс активного долголетия разрабатывался для применения в странах Европы, и, соответственно, опирался на данные европейских опросов населения: Европейского социального исследования (ESS) [12], Европейского исследования рабочей силы (LFS) [13], Европейского исследования доходов и условий жизни (SILC) [14], Европейского исследования качества жизни (EQLS) [15]. Для анализа процесса активного долголетия в России по методике AAI данные часто бывают не доступны в той форме, которую требует оригинальная методика. Это связано с тем, что Россия присутствует только в пяти из 8 волн Европейского социального исследования. Соответственно, проследить динамику активного старения на основе данных ESS можно, но с суще- 
ственными пробелами. Что же касается остальных трех опросов, на которые опирается Индекс активного долголетия, Россия не входит в число стран, где проводятся обследования. Соответственно, для оценки параметров активного долголетия в нашей стране требуется использование либо аналогичных вопросов из других баз данных - Росстата, Переписи населения, Комплексного обследования условий жизни населения [16], Российского мониторинга экономического положения и здоровья населения НИУ ВШЭ [17], либо использование прокси-индикаторов.

В каждом из указанных социологических обследований вопросы формулируются по-разному, опрашиваются респонденты не во всех регионах, либо количество пожилых людей определенного возраста и пола, попавших в выборку по региону, оказывается слишком мало для распространения результатов исследования на генеральную совокупность. Например, в седьмой волне обследования ESS-2012 возрастная подгруппа женщин старше 70 лет, проживающих в Северо-Кавказском федеральном округе, состояла из трех индивидов и давала 100\%-ю занятость по данному сегменту для индикатора 1.4. Вряд ли это дает достаточные основания утверждать, что пожилые женщины данного региона действительно настолько вовлечены в трудовую деятельность. Расчеты AАI для России проводятся в последние годы несколькими научными коллективами $[18,19,20]$. Рассчитанные авторами значения индикаторов Индекса активного долголетия на основе последних доступных данных восьмой волны ESS-2016 приведены в таблице.

Для Сибирского федерального округа проблемным доменом становится четвертый. Специфика четвертого домена заключается в том, что он объединяет индикаторы, за которые «ответственны» как сами пожилые люди, так и различные уровни власти, формирующие «age-friendly» среду. В значительной степени домен «Возможности для активного и здорового долголетия» проседает за счет низкого уровня социальных связей.

Согласно методике Индекса активного долголетия, социальные связи измеряются как процент пожилых людей старше 55 лет, лично общающихся с друзьями, родственниками или коллегами как минимум раз в месяц. Несмотря на достаточно низкую частоту такого общения, заявленную в данном индикаторе, менее 57 \% сибиряков могут себе его позволить. Отсутствие социальной вовлеченности может провоцировать переживания одиночества, что было подтверждено социальными опросами Международной лаборатории технологий улучшения благополучия пожилых людей ТПУ. Низкий уровень вовлеченности и относительно высокий уровень одиночества среди пожилых людей также получили подтверждение в ходе экспертных семинаров проведенных с участием пенсионеров и социальных работников. Эксперты оценили уровень одиночества пожилых людей как высокий (более 25\% всех участников) и средний (более 50 \% всех участников). В ходе экспертных семинаров, посвященных выявлению степени удовлетворенности пожилых людей социальной политикой, участники высказали мнение, что степень удовлетворенности социальной политикой в отношении пожилых людей не заслуживает не только высоких, но и выше среднего уровня оценок. При этом пожилые люди в среднем дали более пессимистичные оценки (63\% опрошенных оценили степень удовлетворенности социальной политикой в отношении пожилых людей как низкую), а в части ответов (5 \%) фигурирует оценка степени удовлетворенности социальной политикой среднего в отношении пожилых людей на критически низком уровне. В ответах работников социальных служб преобладающими (78 \%) были оценки среднего уровня. 
Таблица. Индикаторы Индекса активного долголетия в России и в Сибирском федеральном округе (2016)

Table. Active Ageing Index indicators for Russia and Siberian Federal district (2016)

\begin{tabular}{|c|c|c|}
\hline Индикаторы/Indicators & $\begin{array}{l}\text { СФО } \\
\text { Siberian Federal } \\
\text { district }\end{array}$ & Россия/Russia \\
\hline Занятость/Employment & 22,74 & 25,64 \\
\hline 1.1. 55-59 лет & 49,80 & 56,10 \\
\hline 1.2. 60-64 года & 25,80 & 29,82 \\
\hline 1.3. 65-69 лет & 12,85 & 13,83 \\
\hline 1.4. 70-74 года & 2,50 & 2,81 \\
\hline Участие в жизни общества/Participation in society & 13,84 & 12,80 \\
\hline 2.1. Добровольческая деятельность/Voluntary activities & 1,60 & 1,70 \\
\hline 2.2. Забота о детях и внуках/Care to children, grandchildren & 43,6 & 39,6 \\
\hline 2.3. Забота о пожилых/Care to older adults & 6,10 & 5,30 \\
\hline 2.4. Политическое участие/Political participation & 3,57 & 4,44 \\
\hline $\begin{array}{l}\text { 3. Независимая, здоровая и безопасная жизнь } \\
\text { Independent and secure living }\end{array}$ & 37,47 & 36,86 \\
\hline 3.1. Физическая активность/Physical exercise & 3,51 & 3,43 \\
\hline $\begin{array}{l}\text { 3.2. Отсутствие неудовлетворенных потребностей в медицинской и } \\
\text { стоматологической помощи } \\
\text { No unmet needs of health and dental care }\end{array}$ & 70,7 & 70,7 \\
\hline 3.3. Независимое проживание/Independent living arrangements & 93,1 & 92,3 \\
\hline 3.4. Относительный средний доход/Relative median income & 41,7 & 37,1 \\
\hline 3.5. Отсутствие риска бедности/No poverty risk & 29,5 & 37,6 \\
\hline $\begin{array}{l}\text { 3.6. Отсутствие материальной депривации } \\
\text { No material deprivation }\end{array}$ & 90,3 & 89,95 \\
\hline 3.7. Физическая безопасность/Physical safety & 67,00 & 71,45 \\
\hline 3.8. Обучение в течение жизни/Lifelong learning & 1,53 & 4,4 \\
\hline $\begin{array}{l}\text { 4. Возможности для активного и здорового долголетия } \\
\text { Capacity and enabling environment for active ageing }\end{array}$ & 57,26 & 60,29 \\
\hline $\begin{array}{l}\text { 4.1. Относительная ожидаемая продолжительность жизни в возрасте } \\
55 \text { лет/RLE achievement of } 50 \text { years at age } 55\end{array}$ & 45,22 & 46,88 \\
\hline $\begin{array}{l}\text { 4.2. Доля лет здоровой жизни в относительной ожидаемой продол- } \\
\text { жительности жизни в возрасте } 55 \text { лет } \\
\text { Share of healthy life years in the RLE at age } 55\end{array}$ & 84,40 & 84,40 \\
\hline 4.3. Психологическое благополучие/Mental well-being & 46,45 & 51,64 \\
\hline $\begin{array}{l}\text { 4.4. Использование информационно-коммуникационных технологий } \\
\text { Use of ICT }\end{array}$ & 24,40 & 23,70 \\
\hline 4.5. Социальные связи/Social connectedness & 56,90 & 67,60 \\
\hline 4.6. Уровень образования/Educational attainment & 83,20 & 86,70 \\
\hline Индекс активного долголетия/Overall AAI & 28,00 & 29,20 \\
\hline
\end{tabular}




\section{Дискуссия}

Системных исследований параметров старения населения в России крайне мало. В основном представлены результаты локальных социальных опросов пожилых людей и базовые статистические показатели оценки социально-экономического положения старшего поколения, не связанные непосредственно с социологическими исследованиями. Применение зарубежных методик сопряжено с существенными методологическими трудностями в силу дефицита фактических данных и различий в методологических подходах. Таким образом, предлагаемый методологический подход обеспечивает комплексность исследования за счет:

а) использования широкого спектра методов научного исследования, позволяющих провести анализ как объективных социально-экономических показателей качества жизни пожилых людей, так и субъективной удовлетворенности данной категории населения качеством жизни;

б) включения в анализ всех базовых факторов активного долголетия: занятости, социального участия, независимой и безопасной жизни, наличия среды, обеспечивающей реализацию потенциала пожилых людей в обществе;

в) адаптации международных методик оценки долголетия, что позволяет получить совокупность сопоставимых данных для международных и региональных сопоставлений и в дальнейшем разработать программу мероприятий для повышения качества жизни пожилых людей в РФ с учетом практического опыта европейских стран.

\section{Заключение}

Сохранение и поддержание качества жизни граждан предпенсионного и пенсионного возрастов не гарантировано безусловно существующей пенсионной системой и системой социальной поддержки. Комплексная оценка активного долголетия с использованием методологии АAІ позволяет определять относительно благополучные домены системы активного долголетия в регионе, и домены, в которых необходимо активизировать усилия самих граждан и институтов поддержки. В ходе проведенного исследования было выявлено, что для Сибирского федерального округа доменами с наименее задействованным потенциалом являются занятость и среда активного старения, вполне доступные улучшающим воздействиям со стороны региональных властей.

Исследование выполнено при поддержке Российского фонда фундаментальных исследований (проект № 19-410-700003 p_a 2019).

\section{СПИСОК ЛИТЕРАТУРЫ}

1. Walker A., Maltby T. Active ageing: a strategic policy solution to demographic ageing in the European Union // International Journal of Social Welfare. - 2012. - № 21. - P. 117-130.

2. Harper S. The Reformation of Age and Ageing // Journal of Population Ageing. - 2017. - № 10 (3). P. 201-205.

3. Zaidi A., Howse K. The Policy Discourse of Active Ageing: Some Reflections // Journal of Population Ageing. - 2017. - № 10 (1). - P. 1-10.

4. Global strategy and action plan on ageing and health - World Health Organization, 2017. URL: https://www.who.int/ageing/WHO-GSAP-2017.pdf?ua=1 (дата обращения 24.03.2019).

5. Cosco T., Howse K., Brayne C. Healthy ageing, resilience and wellbeing // Epidemiology and Psychiatric Sciences. - 2017. - V. 26. - Iss. 6. - P. 579-583. DOI: https://doi.org/10.1017/S2045796017000324

6. Malanina V.A., Frolova E.A., Hu Lei. Social and Economic Activity of the Elder Generation in Tomsk Region // The European Proceedings of Social \& Behavioural Sciences (EpSBS). - 2017. - V. 19: Lifelong 
Wellbeing in the World (WELLSO 2016). - P. 217-222. URL: http://dx.doi.org/10.15405/epsbs.2017.01.29 (дата обращения 24.03.2019).

7. Frolova E., Malanina V. Social Wellbeing of Elderly People in Russia // SHS Web of Conferences. - 2016. V. 28. - P. 1-5. URL: http://dx.doi.org/10.1051/shsconf/20162801038 (дата обращения 24.03.2019).

8. Индикатор человеческой жизни, 2017 // Российский демографический лист 2019. URL: http://populationrussia.ru/data/RussianDemographicDataSheet2019_web.pdf (дата обращения 20.03.2019).

9. Старшее поколение // Федеральная служба государственной статистики. URL: http://www.gks.ru/wps/ wcm/connect/rosstat_main/rosstat/ru/statistics/population/generation/ (дата обращения 20.03.2019).

10. Active Ageing Index 2012. Concept, Methodology, and Final Results. Research Memorandum / A. Zaidi, K. Gasior, M. Hofmarcher, O. Lelkes, B. Marin, R. Rodrigues, A. Schmidt, P. Vanhuysse, E. Zolyomi // Methodology Report, European Centre. - Vienna, March 2013. URL: http://citeseerx.ist.psu.edu/ viewdoc/download?doi=10.1.1.360.9488\&rep=rep1\&type=pdf (дата обращения 24.03.2019).

11. Azghar Zaidi. Active Ageing Index 2014: Analytical Report // UNECE/European Commission. 2015. URL: http://www.academia.edu/12446281/Active_Ageing_Index_2014_-_Analytical_Report (дата обращения 29.03.2019).

12. European Social Survey (ESS). 2016. URL: http://www.europeansocialsurvey.org/ (дата обращения 29.03.2019).

13. European Union Labour Force Survey (EU LFS) URL: https://ec.europa.eu/ eurostat/web/microdata/european-union-labour-force-survey (дата обращения 24.03.2019).

14. European Union Statistics on Income and Living Conditions (EU-SILC) URL: https://ec.europa.eu/ eurostat/web/microdata/european-union-statistics-on-income-and-living-conditions (дата обращения 29.03.2019).

15. European Quality of Life Surveys (EQLS) URL: https://www.eurofound.europa.eu/surveys/europeanquality-of-life-surveys (дата обращения 24.03.2019).

16. Комплексное наблюдение условий жизни населения - 2016. URL: http://www.gks.ru/free_doc/ new_site/KOUZ16/index.html (дата обращения 24.03.2019).

17. Российский мониторинг экономического положения и здоровья населения НИУ BШЭ. URL: https://www.hse.ru/rlms/ (дата обращения 29.03.2019).

18. Active Ageing Index: a Russian Study / E. Frolova, G. Barysheva, V. Malanina, E. Taran // Building Evidence for Active Ageing Policies / Eds. A. Zaidi, S. Harper, K. Howse, G. Lamura, J. Perek-Białas. Singapore: Palgrave Macmillan, 2018. - P. 409-435 URL: https://www.springer.com/us/ book/9789811060168 (дата обращения 24.03.2019).

19. Varlamova M., Ermolina A., Sinyavskaya O. Active Ageing Index as an Evidence Base for Developing a Comprehensive Active Ageing Policy in Russia // Journal of Population Ageing. - 2017. - V. 10. - № 1. P. 41-71. URL: https://link.springer.com/article/10.1007\%2Fs12062-016-9164-0 (дата обращения 24.03.2019).

20. Varlamova M. Active Ageing Index (AAI) in non-EU countries and at subnational level // UNECE/European Commission. 2018. URL: https://statswiki.unece.org/display/AAI/VI.+Documents+ and+publications?preview=/7628789 /214892608/AAI_Guidelines_final.pdf (дата обращения 20.03.2019).

Поступила 03.05.2019 г. 


\title{
ACTIVE AGEING ASSESSMENT FOR SIBERIAN FEDERAL DISTRICT BASED ON ACTIVE AGEING INDEX METHODOLOGY
}

\author{
Elena A. Frolova ${ }^{1}$, \\ frolova_ea@mail.tsu.ru \\ Elmira R. Kashapova², \\ elmira6280@yandex.ru \\ Elena I. Klemasheva², \\ klemaha@mail.ru \\ Veronika Malanina², \\ milanskaya@mail.ru
}

\author{
${ }^{1}$ National Research Tomsk State University, \\ 36, Lenin avenue, Tomsk, 634050, Russia. \\ 2 National Research Tomsk Polytechnic University, \\ 30, Lenin avenue, Tomsk, 634050, Russia.
}

Elena A. Frolova, Dr. Sc., professor, National Research Tomsk State University.

Elmira R. Kashapova, laboratory assistant, National Research Tomsk Polytechnic University.

Elena I. Klemasheva, laboratory assistant, National Research Tomsk Polytechnic University.

Veronika Malanina, Cand. Sc., associate professor, National Research Tomsk Polytechnic University.

Internationally, the study of the active ageing process has begun recently. In Europe, attempts for a comprehensive quantitative analysis of the process of active ageing were first undertaken in 2010. The aim of this work is to quantify the process of active ageing in Siberian Federal district. The authors revealed the methodological problems of applying the international methodology for assessing active ageing for Russia and sub-regions. Methods. We have used the method of index assessment of socio-economic processes that form the basis of active ageing, in particular, Active Ageing Index. To illustrate certain findings, additional data were obtained from the expert seminars conducted by the International Scientific Educational Laboratory for the Improvement of Wellbeing Technologies of Older Adults at TPU with retirees and social workers. Results. The assessments of Active Ageing Index indicators and domains revealed the untapped potential of active longevity in Siberian Federal District. Significant negative deviations from average Russian values are observed for the employment of older adults, no poverty risk, physical safety, and social connectedness. At the same time, Siberia shows better results in physical activity, relative median income and no material deprivation. Financial welfare indicators show that Siberian older adults are relatively well off compared to younger generation, but low regional income provides for higher poverty risk.

Key words: Active ageing, Active Ageing Index, older adults, Siberian Federal district, Tomsk region, social participation.

The study was supported by the Russian Foundation for Basic Research (project № 19-410-700003 r_a 2019). 


\section{REFERENCES}

1. Walker A., Maltby T. Active ageing: a strategic policy solution to demographic ageing in the European Union. International Journal of Social Welfare, 2012, no. 21, pp. 117-130.

2. Harper S. The Reformation of Age and Ageing. Journal of Population Ageing, 2017, no. 10 (3), pp. $201-205$.

3. Zaidi A., Howse K. The Policy Discourse of Active Ageing: Some Reflections. Journal of Population Ageing, 2017, no. 10 (1), pp. 1-10.

4. Global strategy and action plan on ageing and health - World Health Organization, 2017. Available at: https://www.who.int/ageing/WHO-GSAP-2017.pdf?ua=1 (accessed 24 March 2019).

5. Cosco T., Howse K., Brayne C. Healthy ageing, resilience and wellbeing. Epidemiology and Psychiatric Sciences, 2017, vol. 26, Iss. 6, pp. 579-583. DOI: https://doi.org/10.1017/S2045796017000324

6. Malanina V.A., Frolova E.A., Hu Lei. Social and Economic Activity of the Elder Generation in Tomsk Region. The European Proceedings of Social \& Behavioural Sciences (EpSBS). 2017, Vol. 19. Lifelong Wellbeing in the World (WELLSO 2016). pp. 217-222. Available at: http://dx.doi.org/ 10.15405/epsbs.2017.01.29 (accessed 24 March 2019).

7. Frolova E., Malanina V. Social Wellbeing of Elderly People in Russia. SHS Web of Conferences, 2016 , vol. 28, pp. 1-5. Available at: http://dx.doi.org/10.1051/shsconf/20162801038 (accessed 24 March 2019).

8. Indikator chelovecheskoy zhizni, 2017 [Indicator of human life, 2017]. Rossiyskiy demograficheskiy list 2019. Available at: http://populationrussia.ru/data/RussianDemographicDataSheet2019_web.pdf (accessed 20 March 2019).

9. Starshee pokolenie [Older generation]. Federalnaya sluzhba gosudarstvennoy statistiki [Federal State Statistics Service]. Available at: http://www.gks.ru/wps/wcm/connect/rosstat_main/rosstat/ru/statistics/population/ generation/ (assessed 20 March 2019).

10. Zaidi A., Gasior K., Hofmarcher M., Lelkes O., Marin B., Rodrigues R., Schmidt A., Vanhuysse P., Zolyomi E. Active Ageing Index 2012. Concept, Methodology, and Final Results. Research Memorandum. Methodology Report, European Centre. Vienna, March 2013. Available at: http://citeseerx.ist. psu.edu/viewdoc/download?doi=10.1.1.360.9488\&rep=rep1\&type=pdf (accessed 24 March 2019).

11. Azghar Zaidi. Active Ageing Index 2014: Analytical Report. UNECE/European Commission. 2015. Available at: http://www.academia.edu/12446281/Active_Ageing_Index_2014_-_Analytical_Report (assessed 29 March 2019).

12. European Social Survey (ESS). 2016. Available at: http://www.europeansocialsurvey.org/ (assessed 29 March 2019).

13. European Union Labour Force Survey (EU LFS). Available at: https://ec.europa.eu/eurostat/ web/microdata/european-union-labour-force-survey (assessed 24 March 2019).

14. European Union Statistics on Income and Living Conditions (EU-SILC). Available at: https://ec.europa.eu/eurostat/web/microdata/european-union-statistics-on-income-and-living-conditions (assessed 29 March 2019).

15. European Quality of Life Surveys (EQLS). Available at: https://www.eurofound.europa.eu/surveys/europeanquality-of-life-surveys (assessed 24 March 2019).

16. Kompleksnoe nablyudenie usloviy zhizni naseleniya - 2016 [Comprehensive observation of the living conditions of the population]. Available at: http://www.gks.ru/free_doc/new_site/KOUZ16/index.html (assessed 24 March 2019).

17. Rossiyskiy monitoring ekonomicheskogo polozheniya i zdorovya naseleniya NIU VSHE [Russian Longitudinal Monitoring Survey - HSE]. Available at: https://www.hse.ru/rlms/ (assessed 29 March 2019).

18. Frolova E., Barysheva G., Malanina V., Taran E. Active Ageing Index: a Russian Study. Building Evidence for Active Ageing Policies. Eds. A. Zaidi, S. Harper, K. Howse, G. Lamura, J. Perek-Białas. Singapore, Palgrave Macmillan, 2018. pp. 409-435. Available at: https://www.springer.com/us/book/9789811060168 (assessed 24 March 2019).

19. Varlamova M., Ermolina A., Sinyavskaya O. Active Ageing Index as an Evidence Base for Developing a Comprehensive Active Ageing Policy in Russia. Journal of Population Ageing, 2017, vol. 10, no. 1, pp. 41-71. Available at: https://link.springer.com/article/10.1007\%2Fs12062-016-9164-0 (assessed 24 March 2019).

20. Varlamova M. Active Ageing Index (AAI) in non-EU countries and at subnational level. UNECE/European Commission. 2018. Available at: https://statswiki.unece.org/display/AAI/VI.+Documents+ and+ publications?preview=/7628789/214892608/AAI_Guidelines_final.pdf (assessed 20 March 2019).

Received: 3 May 2019. 